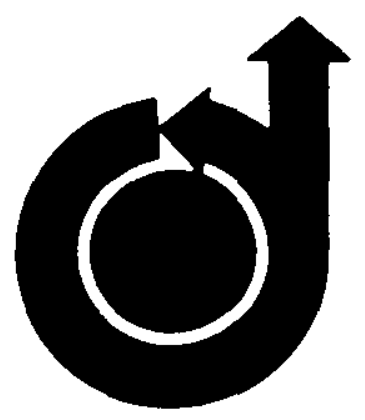

78-1476

\title{
A Method for Localizing Wing Flow Separation at Stall to Alleviate Spin Entry Tendencies
}

T. W. Feistel and S. B. Anderson, NASA

Ames Research Center, Moffett Field, Ca.; and R. A. Kroeger, University of Michigan, Ann Arbor, Mich.

\section{AIAA AIRCRAFT SYSTEMS \\ AND TECHNOLOGY CONFERENCE \\ Los Angeles, Calif./August 21-23, 1978}


T. W. Feistel* and S. B. Anderson ${ }^{\dagger}$

Ames Research Center, NASA, Moffett Field, California

and

R. A. Kroeger ${ }^{\dagger}$

University of Michigan, Ann Arbor, Michigan

\section{ABSTRACT}

A wing leading-edge modification has been developed, applicable at present to single-engine light aircraft, which produces stabilizing vortices at stall and beyond. These vortices have the effect of fixing the stall pattern of the wing such that the various portions of the wing upper surface stall nearly symetrically. The lift coefficient produced is essentially constant to very high angles of attack above the stall angle of the unmodified wing. It is hypothesized that these characteristics will help prevent inadvertent spin entry aftex a stall. Results are presented from recent large-scale windtunnel tests of a complete light aixcraft, both with and without the modification.

\section{INTRODUCTION}

Stalls and spins have continued to be a major cause of fatal and nonfatal accidents involving general aviation aircraft. As discussed in a historical review of stall/spin characteristics, the aerodynamic factors that affect stall/spin behavior have been studied for many years and are well known; however, the incorporation of the proper combination of these factors to provide stall/spin avoidance in current general aviation aircraft has proved to be a difficult design challenge.

A key part of providing acceptable stall/spin behavior involves the wing aerodynamics. Lateral instabilities and the loss of lateral control, common to most aircraft when in a stall, are due to a rapid spread of flow separation on the outer portion of the wing. Many methods to control wing-flow separation have been examined, including aexodynamic twist or geometric washout, wing slots or slats, change in airfoil section, variable thickness ratio, and the use of leading-edge stall strips. Although some of these methods have been somewhat successful in improving stall/spin behavior, the increased complexity of the wing design and loss of performance have acted as deterrents to widespread acceptance by the general aviation industry.

Recently an improvement in post-stall aerodynamic flow control has been made in a research program conducted jointly at Ames Research Center and at the University of Michigan. Basically, the concept involves the shedding of vortices at stall at the mid-semispan leading edge, which serves to preserve the lift, both inboard and outboard, to very large angles of attack.

* Research Engineer.

tResearch Assistant for Interagency Programs. Associate Fellow AIAA. AIAA.
Theoretical models of three-dimensional wings, using a nonlinear-lifting-line approach with a simulated stalled wing section, had suggested that strong vorticity would be shed at the edges of the unattached section. A wind-tunnel model was fabricated with partial span slats added along the entixe leading-edge except for a small length neax the mid-semispan. These differences in leadingedge configuration were intended to produce a strong streamwise vorticity around the stalled section and thus, due to a decrease in the local induced angle of attack, keep the other areas attached to high angles of attack. By varying the spanwise position and width of the unslatted section, a post-stall lift curve shape could be produced, which varied from practically flat on top to double-peaked, depending on the spanwise position of the gap in the leading-edge slats.

This mid-semispan flow-control technique was first developed in experiments in the University of Michigan 5- by 7-Foot Wind Tunnel and in the NASAAmes 7- by 10-Foot wind Tunnel.

A second series of tests was performed in the NASA-Ames $7-$ by 10-Foot Wind Tunnel; the results are reported in Ref. 2. In these studies, using a half-span model, the slats were replaced by leading-edge gloves which added camber and a larger xadius to the leading edge, similar to a GAW-1 airfoil section. The results showed similar flow control capabilities but the effect was not quite as dramatic on the post-stall lift curve as the slats. However, the gloves were capable of producing a flat-top lift curve without showing a perceptible drag penalty with respect to the clean wing. In addition, they wexe simple enough to constitute an acceptable type of add-on to a general aviation production aircraft. Subsequent wind-tunnel studies of a full-span wing in the NASA-Ames 7- by 10Foot Wind Tunnel showed that sideslip did not significantly alter the effectiveness of this flowcontrol concept.

As a next step, the decision was made to test the flow-control method on a typical light airplane in the NASA-Ames $40-$ by 80 -Foot wind Tunnel, both with and without engine power and with various control surface deflections. This paper presents and discusses some results of these recent studies. The aircraft chosen was a Beechcraft Musketeex, Model 23A. A photograph of the aircraft/windtunnel model mounted in the tunnel is shown in Fig. 1.

FULL-SCALE WIND-TUNNEI TESTS

The aircraft was modified by attaching a removable fiberglass leading-edge glove which was installed in segments. The design of the glove was similax to that used in the earlier 7- by 10-foot wind tunnel tests, i.e., by matching the nose of a GAW-1 airfoil to the leading edge of the wing such 
that the upper surfaces of the two airfoils approximately coincide over 20-30\% of the chord (a sketch is shown in the lower part of $F$ ig. 2). This results in a larger leading-edge radius as well as greater camber at the nose; the lower surface is faired flat so that it blends with the bottom of the wing at about $30 \%$ chord. This simple modification is by no means optimum, but it has been shown to delay leading-edge separation to significantly higher angles of attack.

The leading-edge glove segments were designed so they could be removed and rearranged to produce an unprotected gap, varying from $1 / 16$ to $1 / 4$ of the semispan in width, at various spanwise positions on each of the wings. A sketch of the layout and nomenclature is shown in Fig. 2. Figure 3 is a close-up photograph of a typical modification. The location and width of the unprotected gap were vaxied systematically during the exploratory part of the tests. These tests wexe run with the horizontal tail removed, in order to focus on the wing characteristics, at an airspeed of about $77 \mathrm{mph}$ (124 kph).

\section{Results with Modified Leading-Edge and for Basic Ajrcraft}

The most desirable leading-edge modification configuration tested in this phase, based on the shape of the lift curve and the rolling moments produced at stall, was approximately the same as that used in the earlier $7-$ by 10 -foot wind tunnel tests with a semispan wing, ${ }^{2}$ i.e., a $1 / 8$ semispan gap located just inboard of the mid-semispan (position 4 in Fig. 2).

\section{Longitudinal Characteristics}

The tail-off lift curve for this configuration is shown in Fig. 4a, along with the basic tail-off aircraft characteristics for comparison in Fig. $4 \mathrm{~b}$. (Note that these data are for the conflguration with tail off, power off, and. flaps up so that wingbody effects only are being shown.) It can be seen that both the modified and unmodified configurations have approximately the same $C_{I_{\max }}$. The shape of

the top of the lift curve, however, is quite different. The lift of the modified configuration, instead of steadily decreasing, remains essentially constant to an angle of attack of about $32^{\circ}$. It is hypothesized that this characteristic implies improved roll damping past stall; i.e., from the tuft photos, the flow on the outer portion of the wings stays attached, with separation occurring in the vicinity of the mid-semispan and inboard. The tips then, which are the largest contributors to roll, presumably have a positive $\mathrm{C}_{\mathrm{L}_{\alpha}}$ resulting in

an improved roll damping for the wing. The lift of the basic configuration, on the other hand, falls off steadily after the maximum. This negative slope and the observed tip-flow separation imply negative roll damping as is known to occur in the classic post-stall case.

\section{Flow Visualization}

The tuft photos in Fig. 5 correspond to the lift curves shown in Fig. 4. They illustrate the flow structure ovex the wing for a range of angles of attack from immediately pre-stall to deep poststall. The photos of the unmodified version are on the left and those of the modified are on the right.
Starting with the bottom pair of photos, the angle of attack is $12^{\circ}$. As expected for this pre-stall angle, the flow is about the same on both wings, with a small amount of separation occurring at the trailing edge in the wing root region. The tuft patterns at $\alpha=16^{\circ}$ and $\alpha=20^{\circ}$ (not shown) reveal little to distinguish between the two configurations. At $\alpha=24^{\circ}$, in the next pair of photos shown, the favorable effect of the leading-edge modification is especially well illustrated, with the flow ahead of the aileron breaking down on the unmodified wing while it is still well attached on the modified version; it remains so through $\alpha=$ $28^{\circ}$. In the final set of pictures, at $\alpha=36^{\circ}$, the flow separation at the tip of the modified wing, which was partial at $32^{\circ}$ (not shown), is complete (it is interesting to note that the tuft pattern here is similar to that for the unmodified wing at $\alpha=24^{\circ}$ ).

\section{Lateral Characteristics}

The rolling-moment data for these two configurations with neutral controls, and with some maximum roll control limits for full aileron deflection (represented by the open points at selected angles of attack), are shown in Fig. 6. As would be expected from the tuft photos, the rolling moments for the modified wing (in Fig. 6a) are fairly well-behaved to an angle of attack of about $32^{\circ}$, above which they start to depart. The excursion at $20^{\circ}-21^{\circ}$ (Point " $\mathrm{A}$ ") is thought to be due to the leading-edge stall in the unprotected gap occurring on one wing first. Subsequent tests with a sharper leading-edge radius in the gap have reduced this excursion. For the unmodified wing (in Fig. 6b) the divergence in roll is much more extreme, with large uncontrollable excursions occurring at $22^{\circ}-26^{\circ}$; these excursions are due to asymmetric wing flow separation which was obsexved in the tufts. As can be seen, the aileron effectiveness was significantly higher for the modified wing at the higher angles of attack, with that of the unmodified wing dropping to very low values at $\alpha=28^{\circ}$ to $36^{\circ}$. The yawing moments for both versions (not shown) were relatively small. A cursory look at the contribution of the modification to dihedral effect $\mathrm{C}_{\ell_{\beta}}$ and, to a lesser extent, directional stability $c_{n_{B}}$ (for the configurations with tail on), indicates that they are enhanced somewhat at the higher angles of attack. The sensitivity of the post-stall lateral characteristics of the modified aircraft to small yaw angles is still being investigated.

\section{Results with Two Other Types of Leading-Edge Modifications}

In order to investigate other means of obtaining the same results, two other leading-edge modification schemes were tested, both with a discontinuity at position 4 (Fig. 2) -that position found optimum for the gap in the leading-edge glove.

The first of these consisted of the same leading-edge glove full-span in combination with a large, $1.5 \mathrm{in.}(3.8 \mathrm{~cm})$ wide, horizontally disposed leading-edge spoiler $1 / 8$ semispan long. The data for this variation, along with a sketch, are shown in Figs. 7a and 7b. A somewhat larger drop in $\mathrm{C}_{\mathrm{L}}$ resulted after $C_{\mathrm{L}_{\text {max }}}$, but recovery was good, with 
a reasorabiy flat top con the lift curve. The rolling moments, as shown, look bettex than for the modification presented earlier-probably because of stronger vortices boing shed by the large leadingeage spoiler. The yawing moment (not showr) was small. Further irivestigations are being made to desermine whether similar results can be obtained with à suallex spoilex.

The next variation in the leading-edge modification scinemes investigated resembled the conventional stali pattern control treatment used on current light: aircraft. It employed the basic wing, with no leading-edge glove, but with a $3 / 8$ ir. (0.95 cm) squäre "stall strip" at the same position 4 (Fig. 2). This resulted in the lift curve shown in Fig. $8 a ; C_{\text {max }}$ is lower and occurs at a lower ancile of attack. However, the level of $\mathrm{C}_{\mathrm{I}}$. is maintaired for a few degrees farther than for the basio wing, but beyona $a=22^{\circ}$ it. declinea steadily as before, indicating a probable negative roll darpirg. Rolling momert (Fig. Bb) and yawing moment (not shown) stayea within reasonable bouras.

\section{Charactexistics of the complete Airoraft, with Modi.fied Leasing Edge in the Ianding Approath Configuration}

Data are shown in Fig. 9 to substantiate the effectiveness of the modification for a landing approach condition-that in which it is most likely to be needer. These ata are for the modifiea aircraft with the gap in the leading-sdge glove at. position 4, tail on, with trailing-eñge flaps down to $15^{\circ}$, ancl engine power on at $1800 \mathrm{rpm}$. The effect of the flaps on the shape of the wing lift curve is to procuce a greater decrease in lift, after the maximum, before a plateau is reached. This effect is nulifified somewhat, however, by the addition of the lift of the horizontal taij which is set at constant incidence in these data. It can be seen from fig. 9a, that the maximum lift platoal is high and extencis to an angle of attack of $36^{\circ}$. The roling moment data (Fig. 9b) snow greater excursions thail in the previous figures, partiy due to the presence of the propeliex slipstream; the maxinum. exclarsions, howiever, stay within the $C_{0}=0.03$ limit (cefined as satisfactory in Ref. 3 and shown earlier to be withirl aileron control capability in most cases; at angles below $\alpha=32^{\circ}$. The pitching morent, shown untrimmed about the wing quarter-chore in Fics. 9b, is well-behaved to $\alpha=49^{\circ}$, showing no adverse effect of the leadingexige modification on the contribution of the horizontial tail.
A wing leading-edge modification has been developed that changes tife stall pattern so that the onset of separation is localized at the semispan leading eage. vortices shed at this point are thought to help relieve the flcw on the inboard and outboard portions of the wirg, so that the filow separation pattern is stabilized and stays Eixed to large angles of attack. The resulting aexudynamic characteristics of the airplane are improver ir. Fiost of the important aspect. affecting epin departure. For example, while $C_{I_{\max }}$ is about the same as for the urmodified wing, the shape of the top of the lift curve for the modified wing is ingroved so that it is essentially flat to approxinately $32^{\circ}$ angle of attack. In adation, flow visualization studies showed that the flow over the outboard portion of the wing stays attached to much higher angles, indicating that favorable effects on poststall roll damping would be expected. The poststall excursions of the rolling moment are decreased, so that they stay within acceptable levels to an angle of attack of $28^{\circ}$ to $32^{\circ}$. Yawing moments, likewige, are within zatisfactory limits. Finally, the effectiveness of the aijerons is maintained to higher angles of attack with the modified configuration.

Flight tests propeseo for the near future wili help to deternire if these charasteristics are a substantial aid in preventing spin entry after a stall. Recent radio-controlled model tests at langley Research Center (unpublished) have yielded supporting resuits. Further theoretical work will continue with the goal of developing a method of analytically designing a wing with the desired characteristics for a particular aircraft. Further work is requirea to apply a similar flow-control. technique to other types of aircraft; an arpication to light twins, in particuiar, shoula have a high priority.

\section{REFERENCES}

${ }^{1}$ Anäerson, Seth E., "A Historical Cverview of Stall/Spin Characteristics of General Aviation Aircraft," AIAA Conference on Air Transportation: Technicai perspectives and Forcasts, Ios Angeles, Calif, , August $21-24,1978$.

$i_{\text {Kroeger, R. A. and Feistel, T. W., "Reduction }}$ of Stall-Spin Entry Tendencies Frrough Wing Aerodynanic Design," Society of Automotive Engineers, Paper 760481, Busiress Aircraft. Meting, Apri2 6-9, 1976.

${ }^{3}$ Anderson, Seth. B., "Correlation of Flight and Wind-Tunnel heasurements of Roll-off in Iow-Speed Stalls on a $35^{\circ}$ swept-Wing Aircraft," NACA RM A53G22, 1953 . 


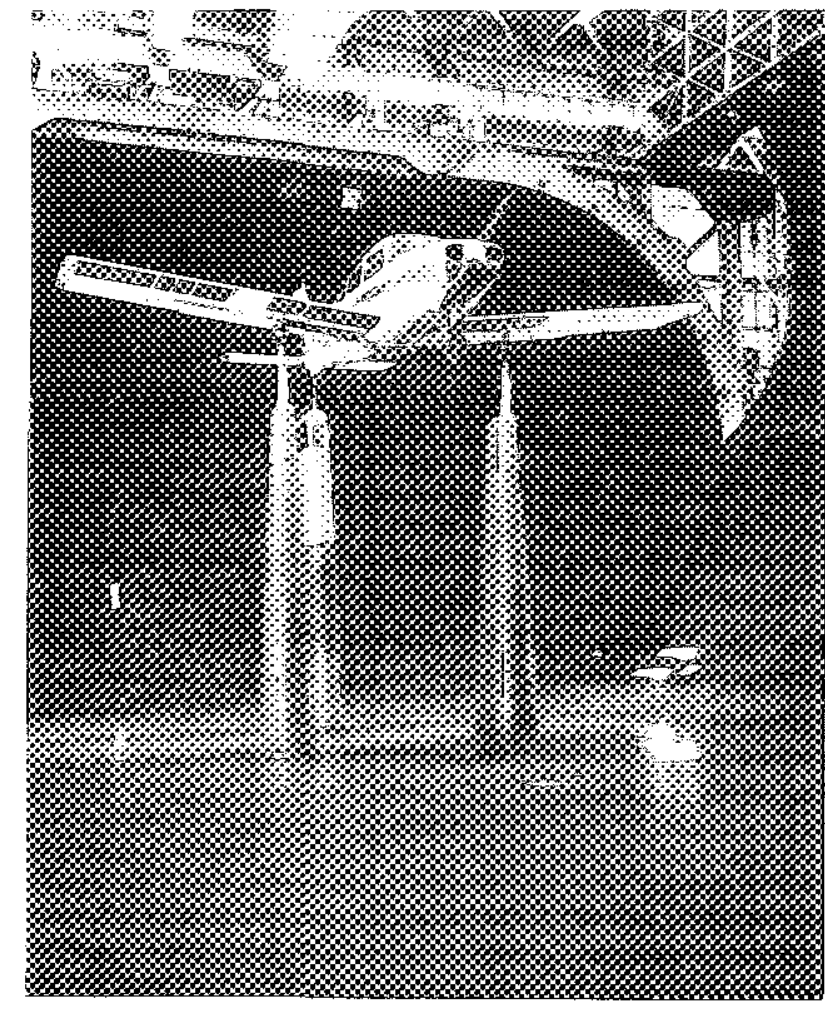

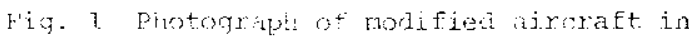
NASA-Amses $4 \mathrm{C}$ by Ro-frot: Wind Funnel.
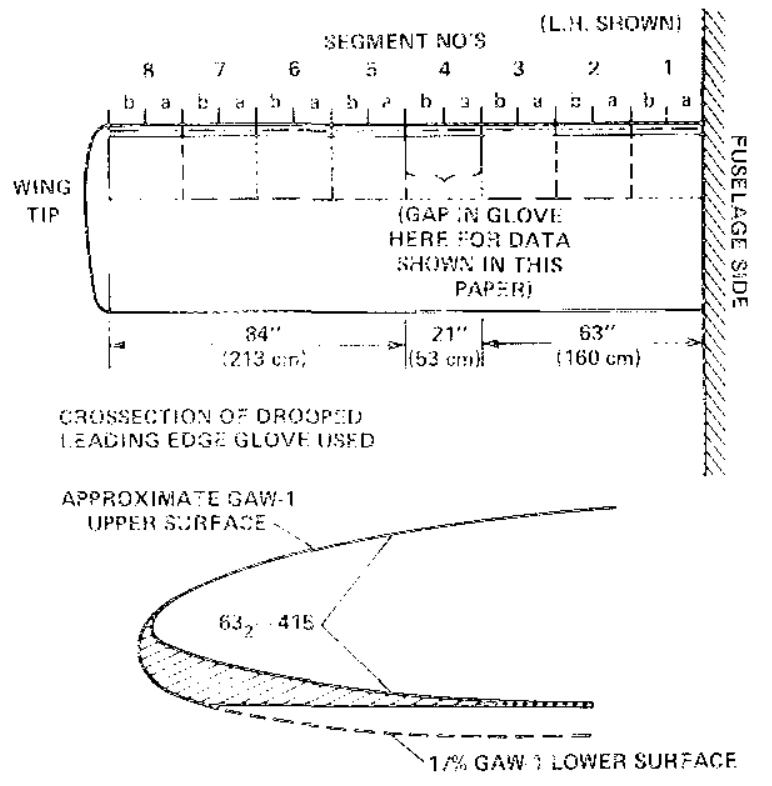

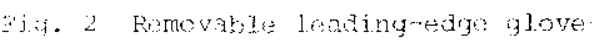
conficuration and romencieture,

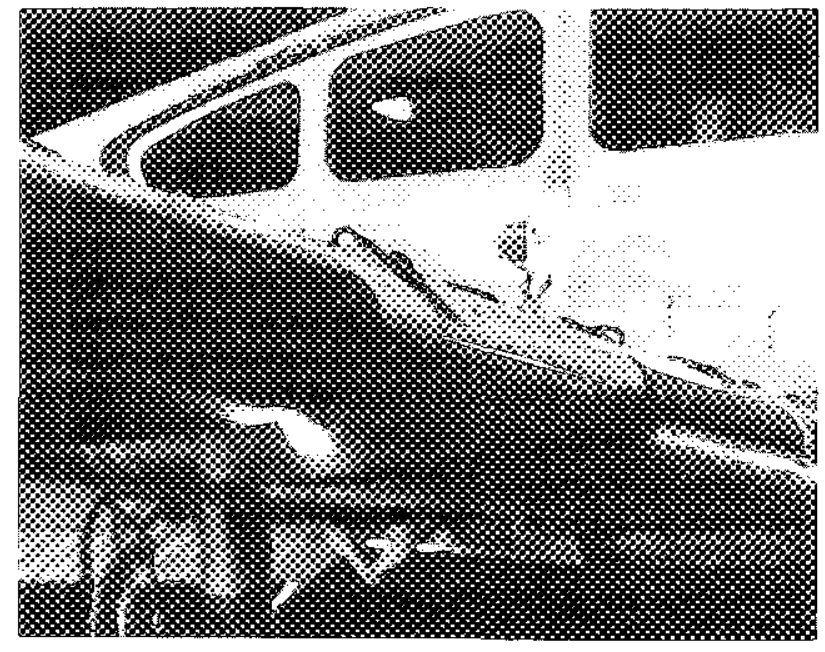

Pjo. 3 chose-up of leading-edge modification.

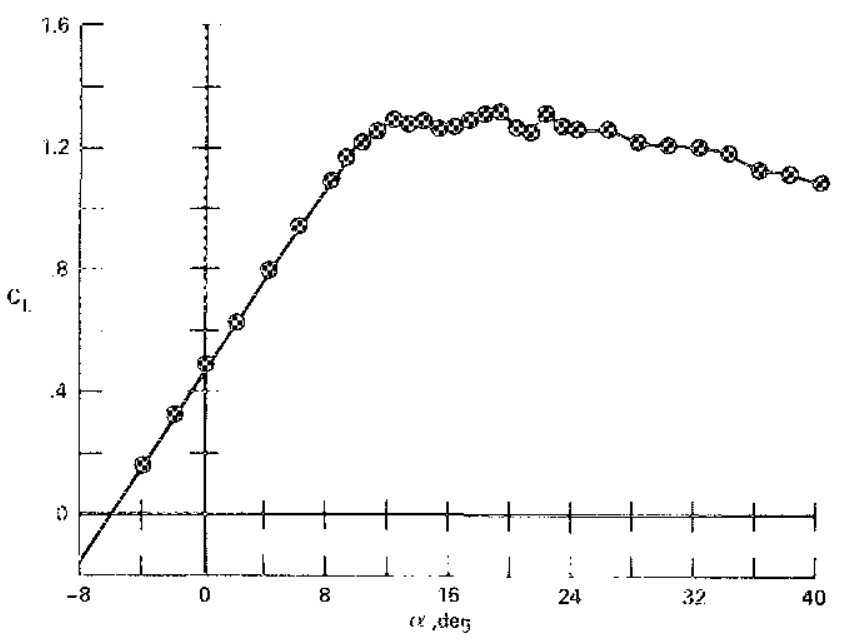

(a) Aircraft: with rodified Jeading edge.

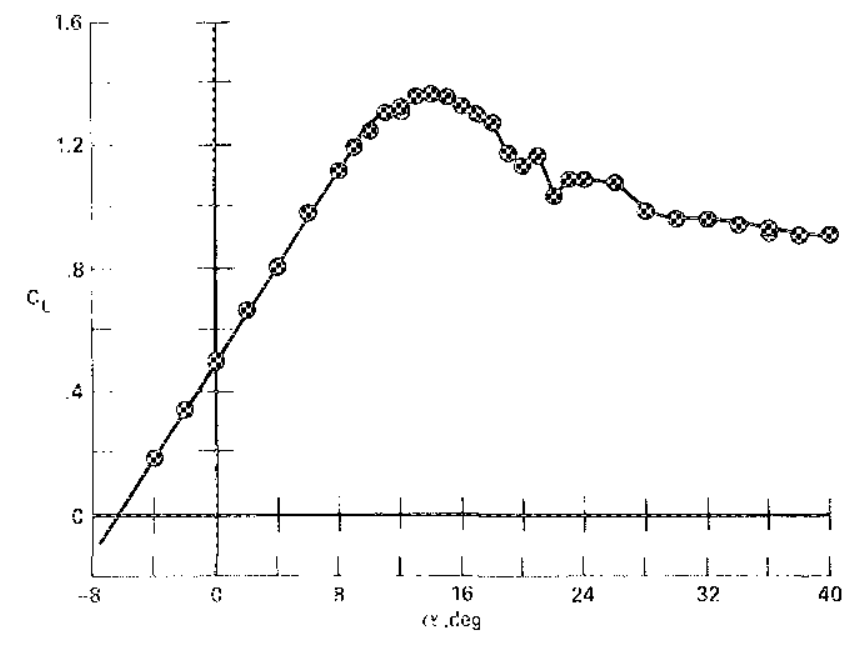

(b) Basic atircraft,

Fig. 4 Taii-off lift curves. 
BASIG ARTRAET
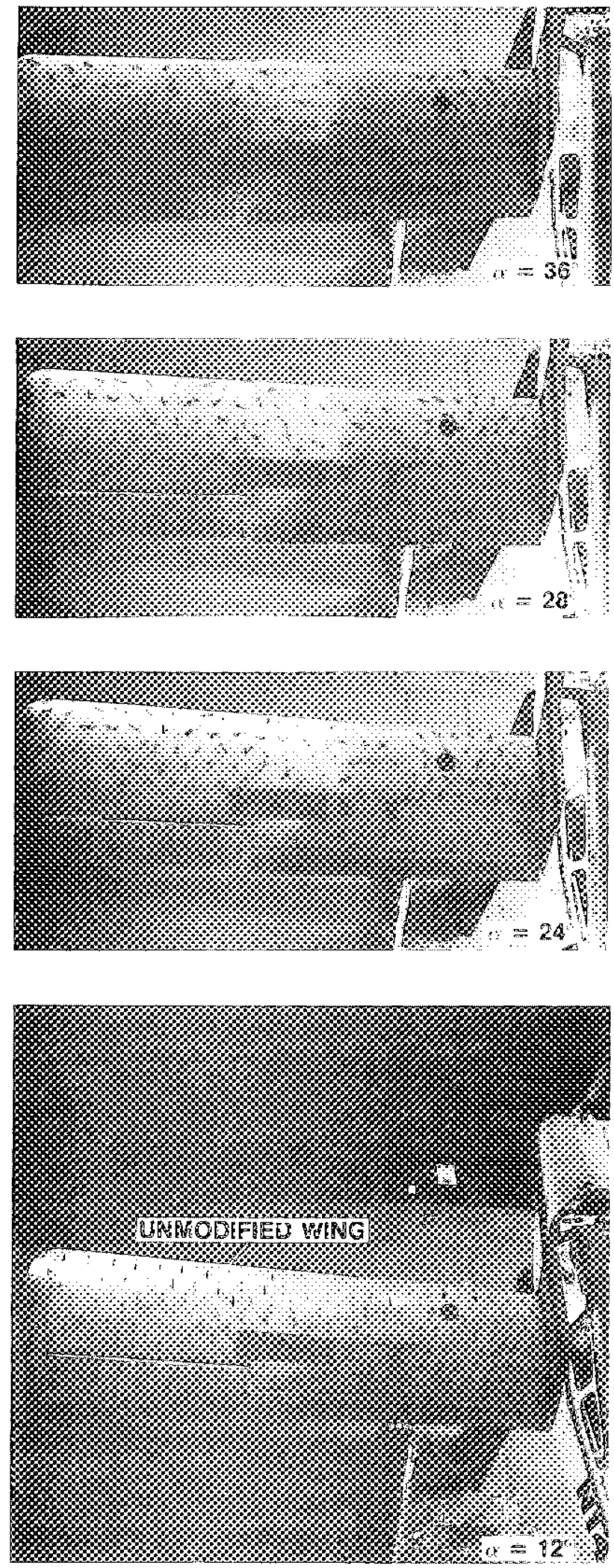

MODHFIED LEADIRG EDGE
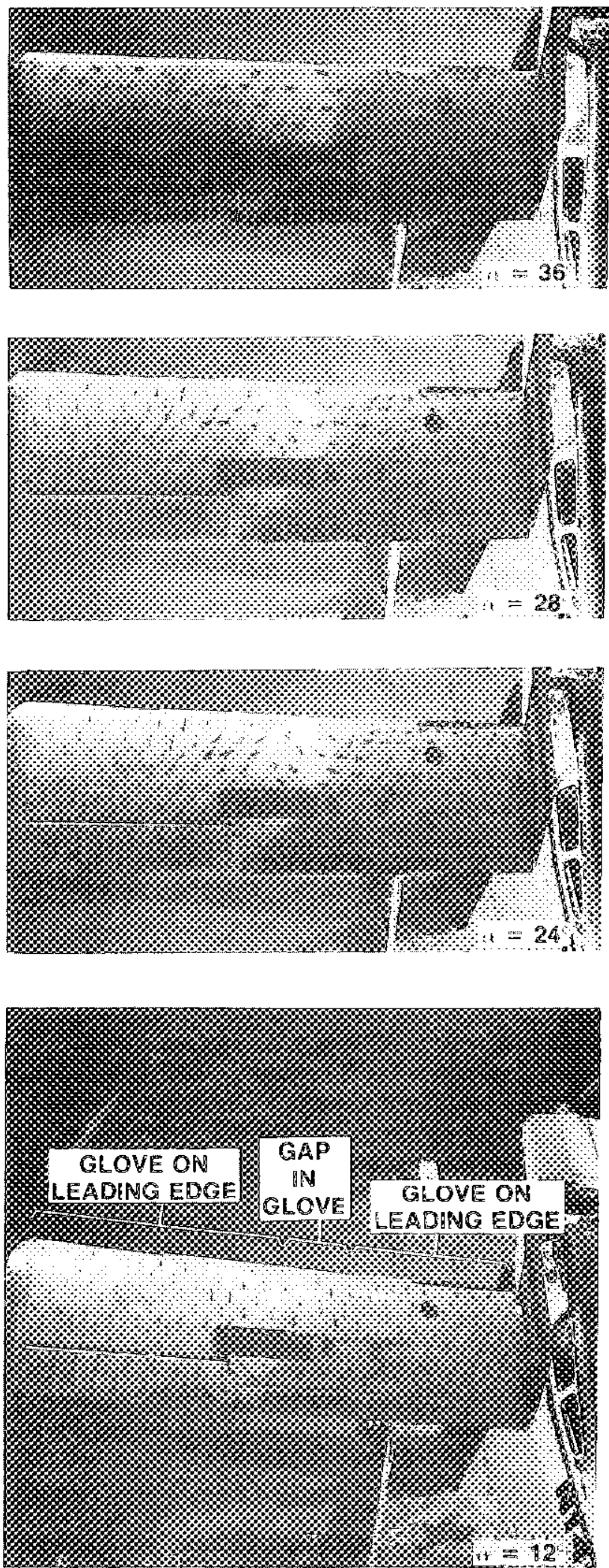

Fig. 5 comparatso tuft photos for modified ard unmodica wings, $\alpha=122^{\circ}-36^{\circ}$. 


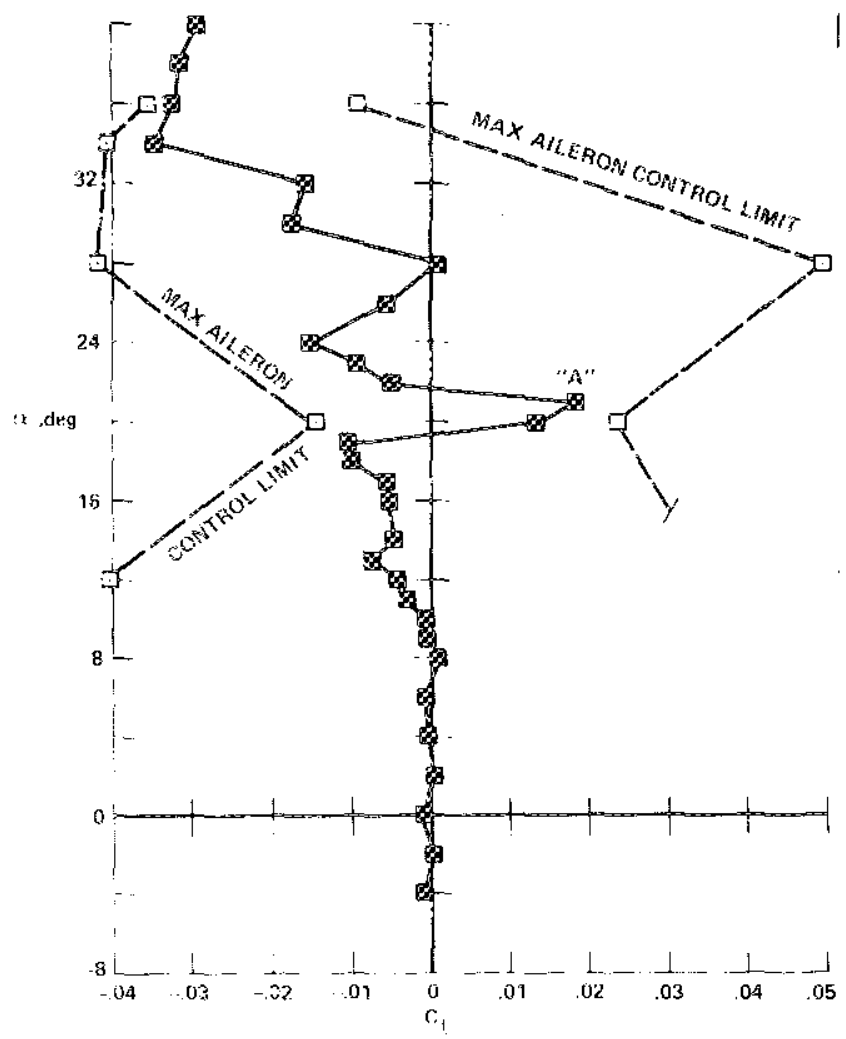

(a) Airoraft with modified leading edge.

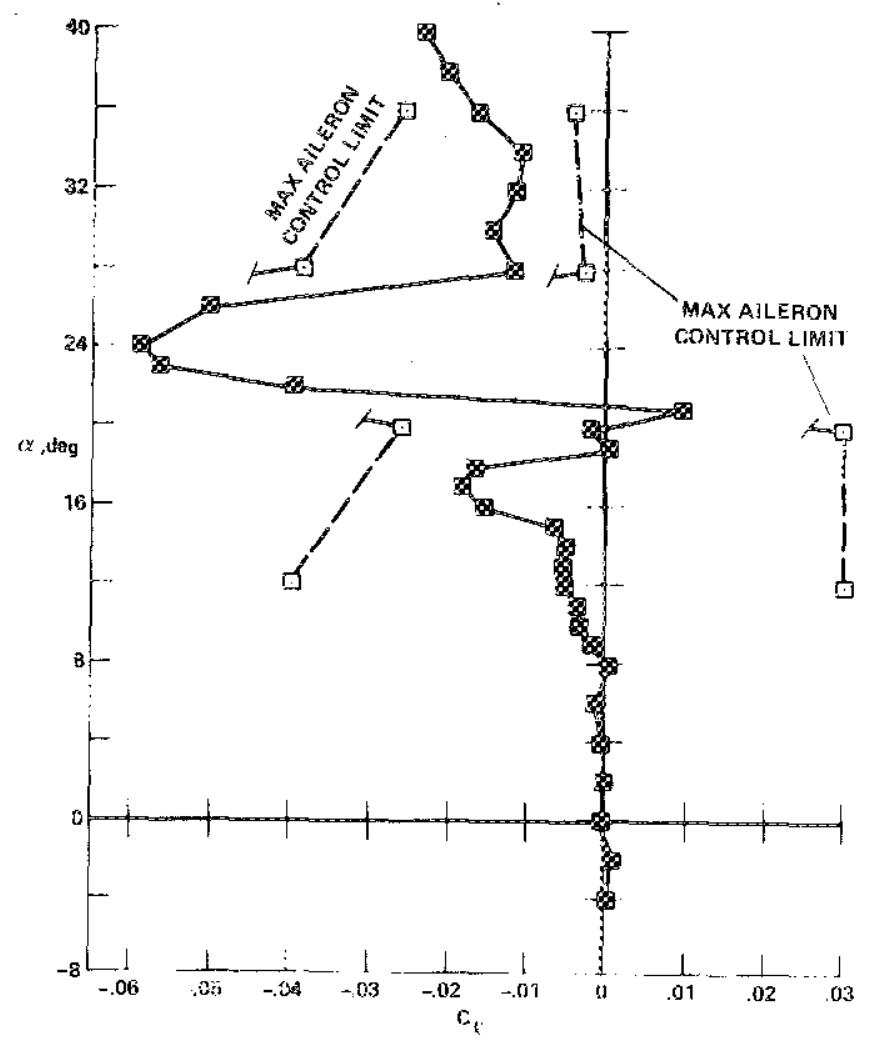

(b) Basid airorate.

Fig. 6 Tailoff rolling monent characteristict.

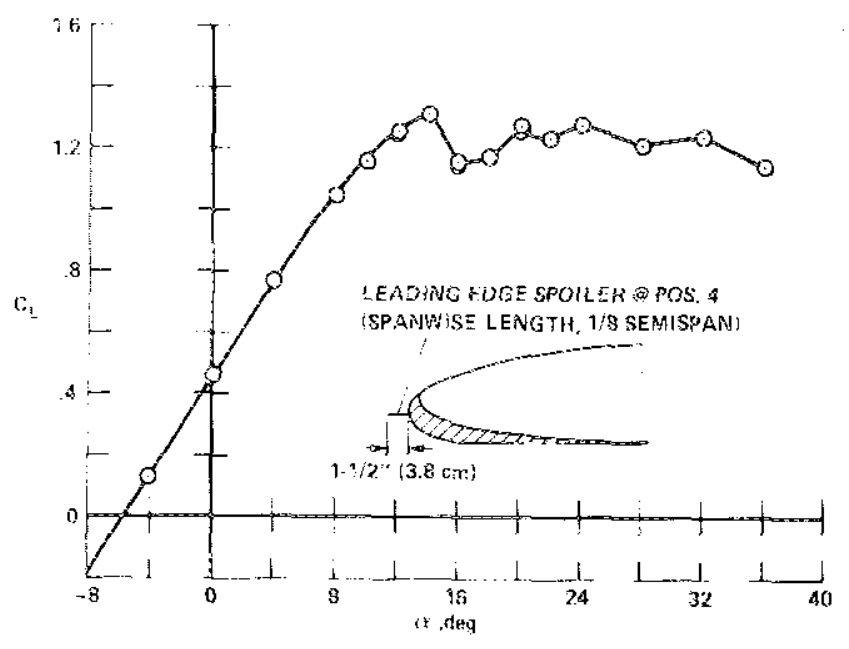

(a) Lifs characteristicis.

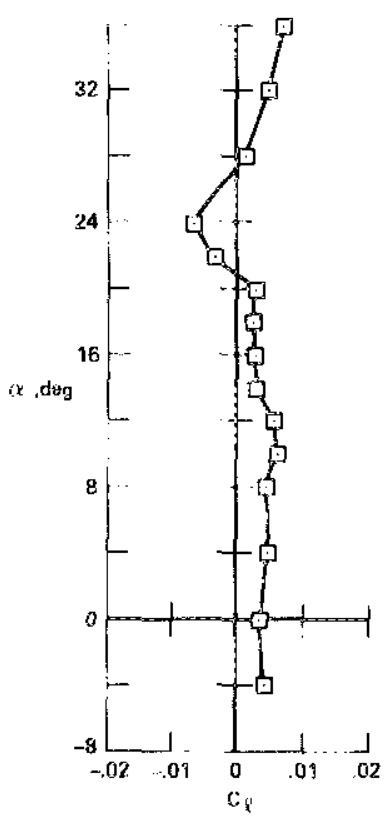

(b) Rolling moments.

Fiq, 7 Airsmet witl; full leating-eage glove, tail-off - spoiner at position 4. 


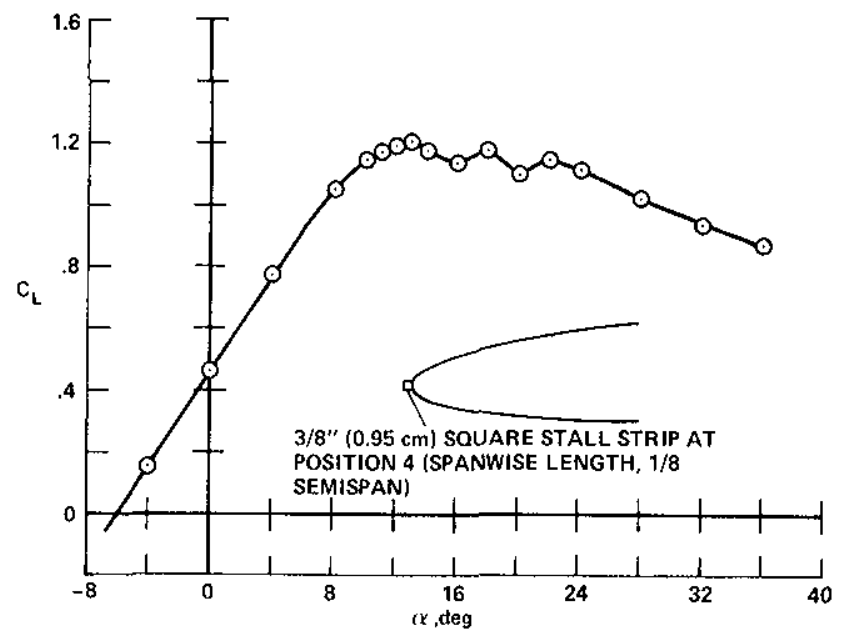

(a) Lift characteristics.

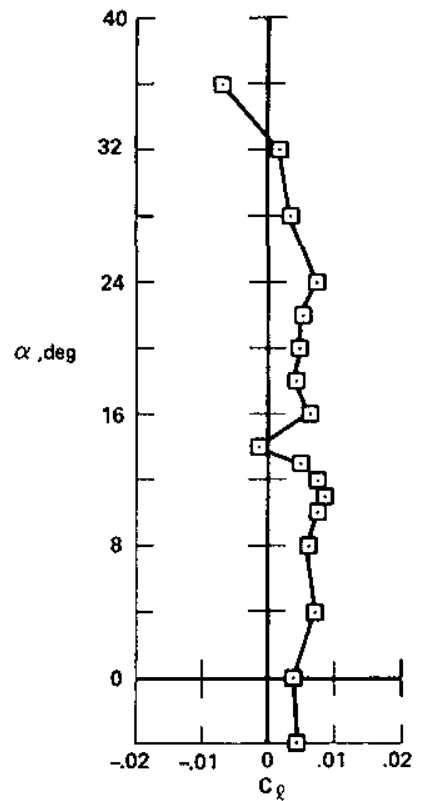

(b) Rolling moments.

Fig. 8 Basic aircraft with stall strip at position 4, tail-off.

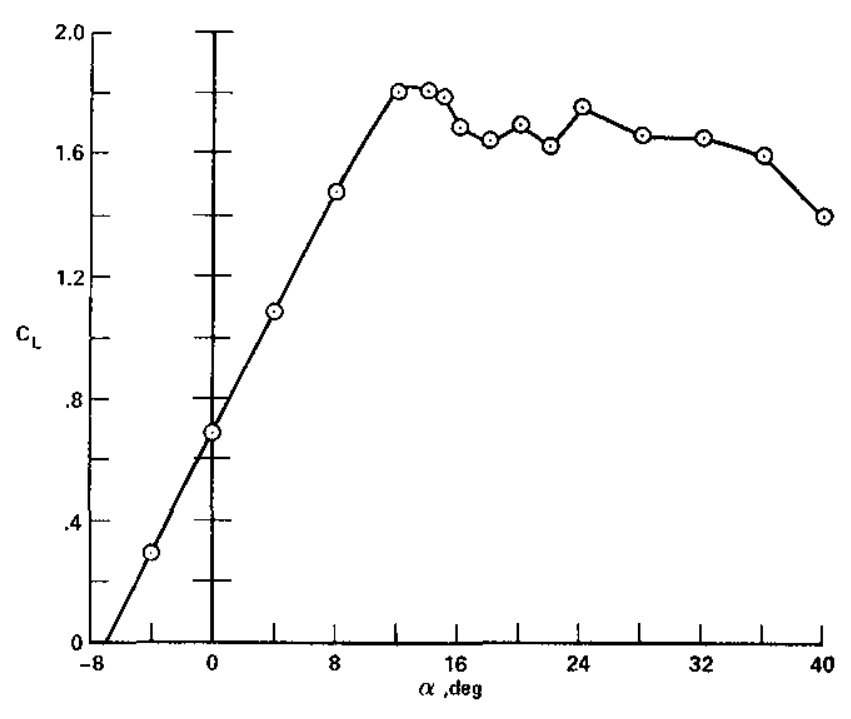

(a) Lift characteristics.
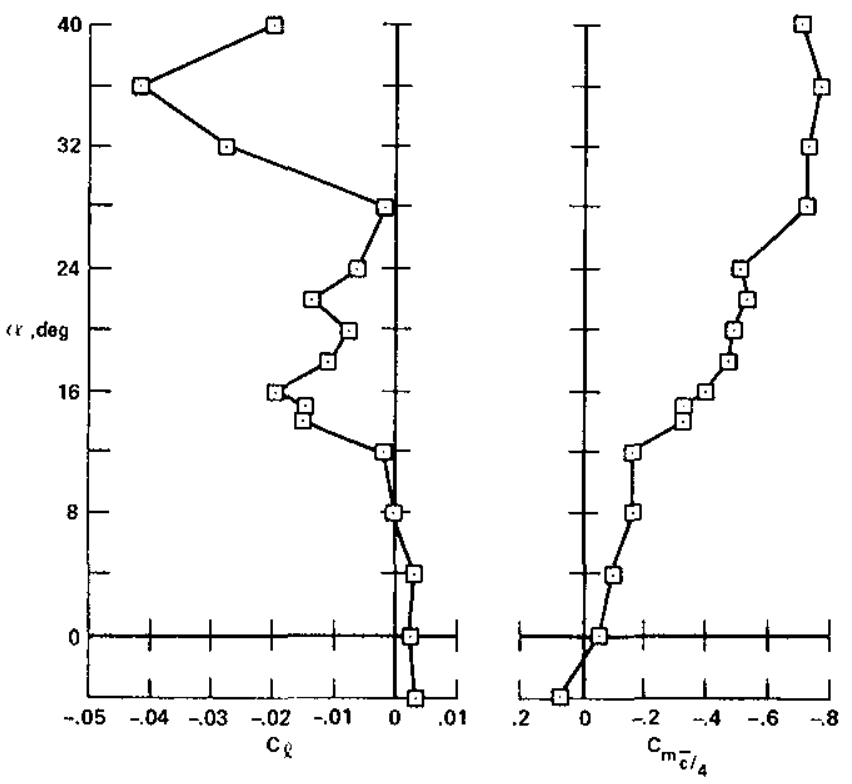

(b) Rolling and pitching moments.

Fig. 9 Complete aircraft with modified leading edge - landing approach condition. 